\title{
Espécies novas de Leuropeltis Hebard, 1921 \\ (Blattellidae, Pseudophyllodromiinae) do estado do Amazonas, Brasil
}

\author{
Sonia Maria Lopes ${ }^{1,2}$ \& Edivar Heeren de Oliveira ${ }^{1}$ \\ ${ }^{I}$ Departamento de Entomologia, Museu Nacional, Universidade Federal do Rio de Janeiro - UFRJ, \\ Quinta da Boa Vista, CEP 20940-040 São Cristóvão, RJ, Brasil \\ ${ }^{2}$ Autor para correspondência: Sonia Maria Lopes, e-mail: sonialfraga@gmail.com
}

LOPES, S.M. \& OLIVEIRA, E.H. New species of Leuropeltis Hebard, 1921(Blattellidae, Pseudophyllodromiinae) from Amazonas State, Brazil. Biota Neotrop, 10(1): http://www.biotaneotropica.org.br/v10n1/en/ abstract?article+bn01110012010.

Abstract: Two new species of Leuropeltis are described and illustrated based on male specimens. External morphology and genitalia are detailed. The genus is registered for the first time from the Brazil, Amazonas State.

Keywords: morphology, Blattaria, Taxonomy, L. amazonensis sp. nov., L. genituspiculatus sp. nov.

LOPES, S.M. \& OLIVEIRA, E.H. Espécies novas de Leuropeltis Hebard, 1921 (Blattellidae, Pseudophyllodromiinae) do Estado do Amazonas, Brasil. Biota Neotrop. 10(1): http://www.biotaneotropica. org.br/v10n1/pt/abstract?article+bn01110012010.

Resumo: Duas espécies novas de Leuropeltis são descritas e ilustradas com base nos espécimens machos. Caracteres morfológicos e genitália são detalhaddos. O gênero é registrado pela primeira vez no Brasil, no Estado do Amazonas.

Palavras-chave: morfologia, Blattaria, Taxonomia, L. amazonensis sp. nov., L. genituspiculatus sp. nov. 


\section{Introdução}

O gênero Leuropeltis foi descrito por Hebard (1921) para identificar indivíduos que apresentam a cabeça muito alargada, olhos proeminentes, o pronoto plano, elíptico e transverso; tégminas ultrapassando em comprimento o ápice dos cercos; campo discoidal levemente convexo com disposição irradiada das veias, com tendência longitudinal; campo anal plano, amplo e alongado; asas com triângulo apical pouco desenvolvido e campo anal dobrado em leque; pernas anteriores longas e espinhosas com o fêmur apresentando na face ântero-ventral uma série de pequenos espinhos que variam em espessura, culminando por mais dois apicais fortes; face pósteroventral com dois espinhos fortes no terço apical e um apical. Pulvilos presentes em todos os artículos tarsais; unhas simétricas e simples; arólios presentes, porém reduzidos.

Pouco se tem estudado sobre esse gênero. Conta atualmente o gênero com três espécies. Após setenta e oito anos, Gutiérrez (1999) rediagnosticou-o e elaborou uma chave para as duas espécies conhecidas (L. atopa Hebard, 1921 e L. gurneyi R.S.Albuquerque, 1964). No mesmo trabalho acrescentou mais uma espécie ( $L$. hebardi) e caracterizou as espécies pela configuração da placa subgenital e a morfologia do esclerito mediano, assinalando sua distribuição geográfica para Guiana Francesa, Venezuela, Bolívia, Paraguai.

Com base em Roth (2003), Klass \& Meier (2006) e Khambhampati (1995), Leuropeltis neste trabalho é mantido entre os Pseudophyllodromiinae sendo considerado parafilético, e da mesma forma considerado por Beccaloni (2007).

Pellens \& Grandcolas (2008) não incluíram Leuropeltis em seu Catálogo. No presente trabalho é registrado pela primeira vez o gênero para o Brasil e são descritas duas espécies (L. amazonensis sp. nov. e L. genituspiculatus sp. nov.) para a região da Amazônia, as quais são apresentadas e ilustradas as estruturas genitais dos machos respectivos.

\section{Material e Métodos}

Para a observação dos exemplares foram examinadas as suas estruturas genitais através da retirada da parte final do abdome dos exemplares macho, utilizando-se técnicas tradicionais para dissecção, descritas em Lopes \& Oliveira (2000). Tais estruturas foram nomeadas com base em Roth (2003). A posição filogenética do gênero seguiu Klass \& Meier (2006). O material analisado foi guardado em microtubos de vidro, contendo glicerina e devidamente acondicionados, junto ao exemplar respectivo, montado em alfinete entomológico, na coleção entomológica no Museu Nacional, Universidade Federal do Rio de Janeiro (MNRJ).

\section{Resultados}

\section{Leuropeltis amazonensis sp. nov. (Figura 1 a-h)}

Coloração geral: castanho-escuro brilhante. Cabeça castanha com ocelos castanho-avermelhados; área de inserção antenal e pulvilos nas pernas esbranquiçados e pós-clípeo com ápice claro. Pronoto com mancha compacta enegrecida e bordos laterais na metade anterior transparente (Figura 1b).

Dimensões (mm): Holótipo $\widehat{\partial}$. Comprimento total. 14,0; comprimento do pronoto. 3,0; largura do pronoto. 4,5; comprimento da tégmina. 13,0; largura da tégmina. 4,0.

Cabeça: triangular, transversa, curta e alargada, olhos grandes e lateralizados (Figura 1a); vértice exposto sob o pronoto em vista dorsal; espaço interocular medindo metade da área que separa as bases de inserção antenal; antenas longas, ultrapassando em comprimento o ápice do abdome. Palpos maxilares com terceiro artículo mais longo que os demais, quinto artículo dilatado e tomentoso.

Tórax: com pronoto transverso, elíptico e com entorno arredondado. Fêmur anterior na face ântero-ventral com duas séries de espinhos, sendo cinco mais fortes que decrescem suavemente até a região mediana e a outra com cinco espinhos menores e dois espinhos apicais grandes e fortes $(5+5+2)$; face póstero-ventral com quatro espinhos fortes, sendo um apical $(4+1)$. Fêmures médio e posterior com cinco a sete espinhos fortes e espaçados, sendo um apical; espinhação semelhante em ambas as faces ventrais; presença de espinho genicular nos dois últimos fêmures citados. Pulvilos presentes em todos os artículos tarsais; unhas simétricas e simples e arólios pequenos. Tégminas longas, campo marginal amplo e alongado; campo escapular estreito e alongado, com disposição venular oblíqua; campo discoidal estreito, com disposição venular longitudinal levemente irradiada; campo anal amplo com seis ou mais veias axilares. Asas com campo costal apresentando ápices dos ramos levemente dilatados; triângulo apical moderadamente desenvolvido e campo anal dobrado em leque.

Abdome: modificação tergal no sétimo segmento com um grupamento de cílios reunidos na região mediana (Figura 1c). Placa supra-anal projetada entre os cercos em forma triangular com leve reentrância medianamente; cercos curtos e alargados (Figura 1e). Placa subgenital levemente assimétrica, apresentando medianamente uma projeção alongada arredondada no ápice com diminutos espinhos em seu entorno; estilos afilados, desenvolvidos e iguais (Figura 1d). Falômero direito, em forma de gancho, com reentrância profunda pré-apical e o ápice arredondado (Figura 1h). Esclerito mediano simples apresentando apicalmente L2d com o ápice afilado (Figura 1g). Falômero esquerdo complexo em forma de V-invertido com braços assimétricos e medianamente esclerotinizado (Figura 1f).

Material examinado: Holótipo ${ }^{\lambda}$, BRASIL, Amazonas, Coari, Rio Uruci; LUC 09; 4 51' 56" S and 65 04' 56" W; 25/I-10/II/1995, P.F. Bührnhein \{et al. \}sic cols. (luz mista de mercúrio) (MNRJ).

Etimologia: O nome da espécie refere-se ao Estado onde foi coletado o exemplar.

Comentário: L. amazonensis sp. nov. é similar à L. atopa Hebard, 1921 com base na análise da modificação tergal no abdome e na configuração da placa subgenital, que apresenta uma projeção mediana apicalmente arredondada, diferindo pela configuração do esclerito mediano.

\section{Leuropeltis genituspiculatus sp. nov. (Figura 2 a-g)}

Coloração geral: Castanho brilhante . Cabeça, antenas e pronoto com abas laterais hialinas e disco central castanho-escuro; olhos negros com nuances em castanho; ocelos claros e amarelados; antenas no ápice com coloração castanho-clara e tomentosidade dourada.

Dimensões (mm): Holótipo $\widehat{\partial}$. Comprimento total. 13,5; comprimento do pronoto. 2,5 ; largura do pronoto. 4,0; comprimento tégmina. 11,0; largura da tégmina. 3,5.

Cabeça: triangular, curta e alongada com olhos grandes e lateralizados (Figura 2a); ocelos bem nítidos; vértice exposto sob o pronoto; espaço interocular amplo, semelhante em tamanho a área que separa as bases das inserções antenais; antenas longas e tomentosas, ultrapassando em comprimento o ápice dos cercos e atingindo o ápice das tégminas quando estão em repouso; palpos maxilares com terceiro artículo menor que o quarto e o quinto, este último dilatado e tomentoso.

Tórax: pronoto elíptico, convexo e elipsóide (Figura 2b). Pernas espinhosas; fêmur anterior na face ântero-ventral com duas séries de espinhos sendo três espinhos maiores seguidos de outra série de cinco mais fortes na região mediana em direção ao ápice onde existem dois espinhos apicais grandes e fortes $(3+5+2)$; face póstero-ventral com quatro espinhos mais finos sendo intercalados por um forte no terço apical e mais um apical um pouco maior $(2+1+2+1)$. Fêmures médio e posterior com três a cinco espinhos robustos, sendo um apical, semelhante em ambas as faces ventrais; espinho genicular presente. Pulvilos presentes em todos os artículos tarsais; arólios presentes e pequenos; unhas simétricas e simples. Tégminas longas com campo marginal, estreito e alongado; campo escapular convexo com disposição venular oblíqua; campo discoidal relativamente estreito, alongado com disposição venular longitudinal; 

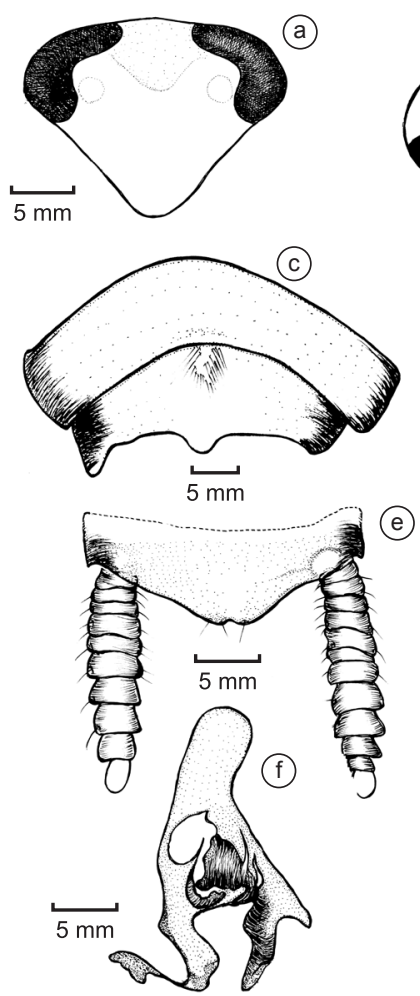

(e)
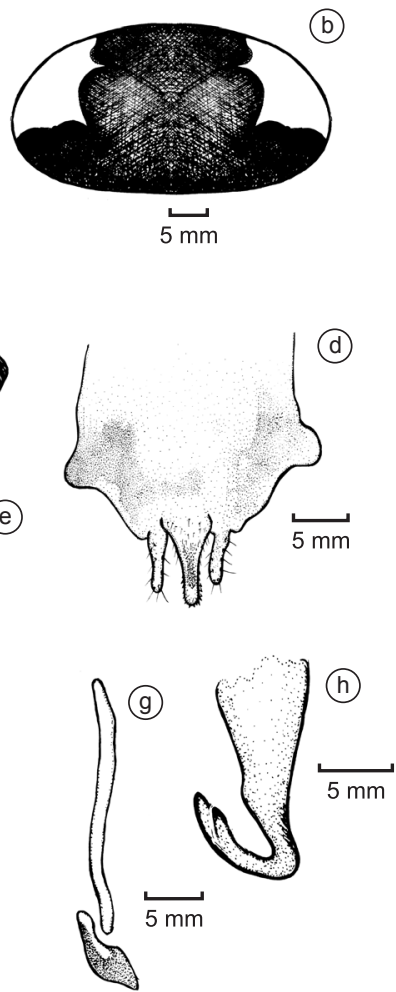

Figura 1. Leuropeltis amazonensis sp. nov. Holótipo ${ }^{\lambda}$. a) cabeça; b) pronoto; c) modificação tergal no abdome no sétimo segmento; d) placa subgenital; e) placa supra anal; f) falômero esquerdo; g) esclerito mediano; e h) falômero direito.

Figure 1. Leuropeltis amazonensis sp. nov. Holotype $\widehat{\partial}$. a) head; b) pronotum; c) abdominal tergal modification; d) subgenital plate; e) supraanal plate; f) left phallomere; g) median sclerite; and h) right phallomere.

campo anal curto e alargado com seis a oito veias. Asas com setor costal apresentando ápices dos ramos da radial levemente dilatados; triângulo intercalar pequeno; campo anal dobrado em leque.

Abdome: ausência de modificação tergal. Placa supra-anal projetada entre os cercos em forma triangular com leve reentrância medianamente. Parapróctos afilados e distintos. Cercos curtos e alargados (Figura 2c). Placa subgenital levemente assimétrica, apresentando medianamente uma projeção afilada com ápice espiniforme e no seu entorno com várias fileiras de espinhos diminutos; estilos alargados, desenvolvidos e diferenciados na forma com espinhos nas margens internas, dorsal e apical (Figura 2e). Falômero direito, em forma de gancho, com reentrância pré-apical acentuada, e o ápice arredondado apicalmente (Figura 2d). Esclerito mediano simples apresentando L2d em forma de foice (Figura 2f). Falômero esquerdo em forma de V-invertido com os braços assimétricos e medianamente esclerotinizado (Figura 2g).

Material examinado: Holótipo $\widehat{o}^{\uparrow}$. BRASIL, Amazonas, Coari, Rio Urucu, Angelim, 5’3’33" S e 65 14' 48”' O, 23/XI-02/XII/1992, P. F. Bührnhein \& N.O. Aguiar cols. (à luz mista de mercúrio).

Etimologia: O nome da espécie deve-se à configuração de várias fileiras de espinhos na margem mediana da placa subgenital.

Comentário: L. genituspiculatus assemelha-se à L. hebardi Gutierrez, 1999 com base na ausência da modificação tergal no abdome e na configuração da projeção mediana da placa subgenital e dela difere pela forma do esclerito mediano que se apresenta falciforme.

\section{Agradecimentos}

À Faperj projeto E-26/171-281/2006, Rede de Insetos - Diversidade biológica da Mata Atlântica do Estado do Rio de Janeiro pelo apoio técnico para digitalização.
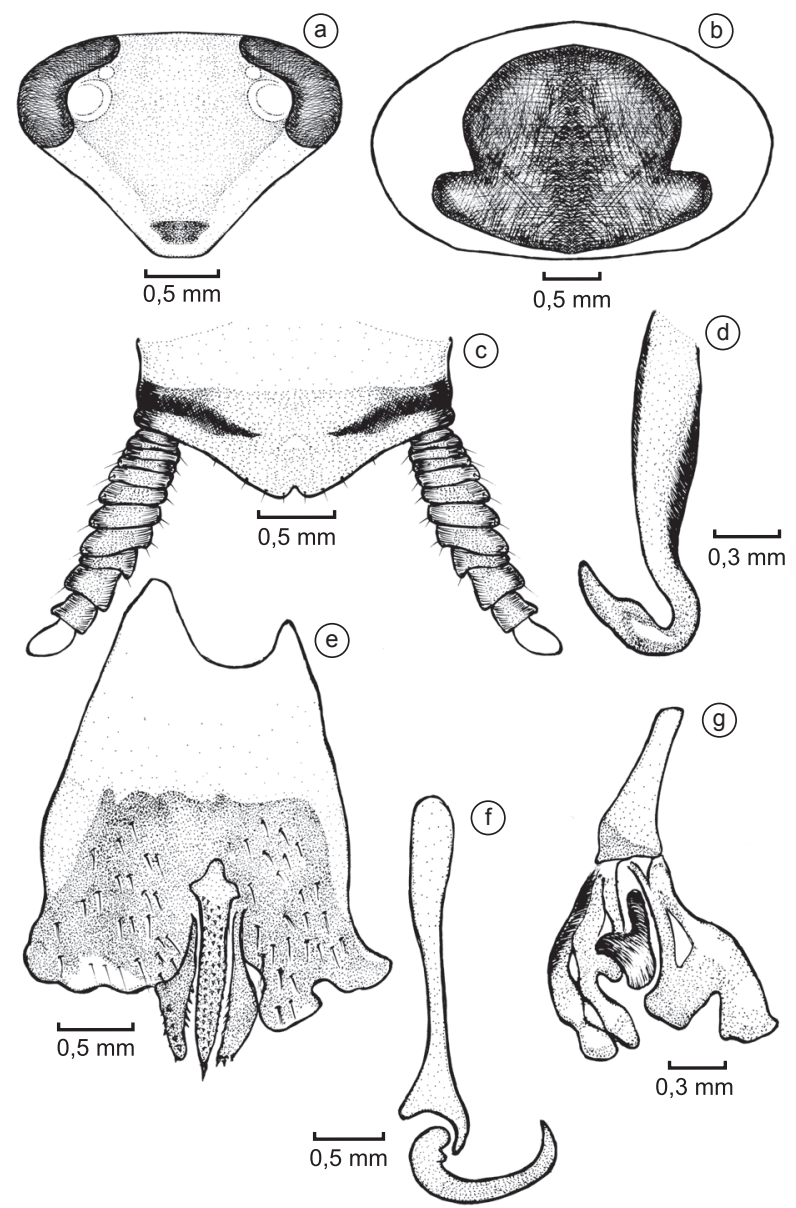

Figura 2. Leuropeltis genituspiculatus sp. nov. Holótipo 3 . a) cabeça; b) pronoto; c) placa supra-anal; d) falômero direito; e) placa subgenital; f) esclerito mediano; e g) falômero esquerdo.

Figure 2. Leuropeltis genituspiculatus sp. nov. Holotype $\delta$. a) head; b) pronotum; c) supra-anal plate d) right phallomere; e) subgenital plate; f) median sclerite; g) left phallomere.

\section{Referências}

BECCALONI, G. W. 2007. Blattodea Species File Online. Version 1.2/3.1. http://blattodea.speciesfile.org (último acesso em 15/10/2007)

HEBARD, M. 1921. South American Blattidae from the Muséum national d'Histoire naturelle, Paris, France. Proc. Acad. Nat. Sci. Philadelphia 73(2): 193-304.

GUTIÉRREZ, E. 1999. The cockroach genus Leuropeltis Hebard (Dictyoptera: Blattellidae: Pseudophyllodromiinae) with a new species from South America. Proc. Acad. Nat. Sci. Philadelphia 149:71-75.

KHAMBHAMPATI, S. 1995. A phylogeny of cockroaches and related insects based on DNA sequence of mitochondrial ribosomal RNA genes. Proc. Acad. Nat. Sci. Philadelphia 92:2017-2020.

KLASS, K.D. \& MEIER, R. 2006. A phylogenetic analysis of Dictyoptera (Insecta) based on morphological characters. Entomol. Abh. 63(1-2):3-50.

LOPES, S.M. \& OLIVEIRA, E.H. 2000. Espécie nova de Eublaberus Hebard, 1919 do Estado de Goiás, Brasil e notas sobre E. marajoara Rocha e SilvaAlbuquerque, 1972 (Blaberidae, Blaberinae). Bol. Mus. Nac. 433:1-5.

ROTH, L.M. 2003. Systematics and Phylogeny of Cockroaches (Dictyoptera: Blattaria). Orient. Insects 37:1-186.

Recebido em 17/09/09

Versão reformulada recebida em 25/01/10

Publicado em 28/01/10 